\title{
Optimization of the Process of Water-Ethanol Extraction of Ethanollignin from Siberian Larch Wood
}

\author{
Alexey V. Rudkovskiy, Svetlana A. Kuznetsova, \\ Nikolai V. Chesnokov and Boris N. Kuznetsov* \\ Institute of Chemistry and Chemical Technology SB RAS \\ FRC "Krasnoyarsk Science Center SB RAS" \\ 50/24 Akademgorodok, Krasnoyarsk, 660036, Russia
}

Received 06.04.2018, received in revised form 18.07.2018, accepted 13.09.2018

It was carried out optimization of the process of water-ethanol extraction of ethanol-lignin from Siberian larch wood by calculation methods. A two-parameter mathematical model of the extrac-tion process based on the central second-order Kono composite plan was created. The influence of two parameters - the concentration of aqueous ethanol and temperature - on the degree of delignification of wood was studied. It was shown that the selected parameters are statistically independent of each other. The response surface is a parabolic cylinder. Optimal conditions for the process of the bark wood extraction which corresponds to the maximum yield of ethanollignin were determined: temperature $220{ }^{\circ} \mathrm{C}$ and ethanol concentration $70 \%$ vol.

Keywords: ethanol-lignin, larch wood, water-ethanol extraction, optimization.

Citation: Rudkovskiy A.V., Kuznetsova S.A., Chesnokov N.V., Kuznetsov B.N. Optimization of the process of water-ethanol extraction of ethanollignin from Siberian larch wood, J. Sib. Fed. Univ. Chem., 2018, 11(3), 436-446. DOI: 10.17516/19982836-0089.

\footnotetext{
(C) Siberian Federal University. All rights reserved

* Corresponding author E-mail address: rudkovsky@indox.ru
} 


\title{
Оптимизация процесса водно-этанольной \\ Экстракции этаноллигнина
}

\section{из древесины лиственницы сибирской}

\author{
А.В. Рудковский, С.А. Кузнецова, \\ Н.В. Чесноков, Б.Н. Кузнецов \\ Институт химии и химической технологии СО РАН \\ ФИЦ «Красноярский научный цуентр СО РАН» \\ Россия, 660036, Красноярск, Академгородок, 50/24
}

\begin{abstract}
Расчетными методами проведена оптимизация процесса водно-этанольной экстракиии этаноллигнина из древесины лиственницы сибирской. Построена двухпараметрическая математическая модель процесса экстракции на основе центрального композитного плана Коно-2. Исследовано влияние на степень делигнификации древесины двух параметров кониентрачии водного раствора этанола и температуры. Показано, что выбранные параметры являются статистически независимыми. Поверхность отклика представляет собой параболический ичлиндр. Определены оптимальные условия процесса экстракиии древесины лиственницы, при которых достигнут максимальный выход этаноллигнина: температура $220{ }^{\circ} \mathrm{C}$ и концентрация этанола $70 \%$ об.
\end{abstract}

Ключевые слова: этаноллигнин, древесина лиственницы, водно-этанольная экстракция, оптимизация.

\section{Введение}

Органосольвентные лигнины, выделенные органическими растворителями из лигноцеллюлозной биомассы, не содержат серы, имеют низкую молекулярную массу и представляют собой ценное сырье для получения продуктов с высокой добавленной стоимостью. Они могут применяться в качестве заменителя нефтяных фенолов при производстве смол [1], для получения широкого класса ароматических соединений и др. [2].

В литературе известны работы, направленные на определение оптимальных параметров органосольвентной варки лигноцеллюлозного сырья $[1,3]$. Необходимо отметить, что для органосольвентной экстракции при этом было использовано различное сырье: древесина сосны [1], древесина осины [2], шелуха миндального ореха [3], древесина эвкалипта [4], пшеничная солома [5], древесина бука [6], древесина тополя [7].

Анализ литературных данных [1-8] показывает, что, несмотря на широкий спектр использованного сырья, основными параметрами, влияющими на выход и качество лигнина, являются природа и концентрация растворителя, продолжительность экстракции и температура.

Оптимальная температура для всех указанных выше видов растительного сырья находится в диапазоне $180-220^{\circ} \mathrm{C}$, а концентрация этанола варьируется в пределах от 55 [4] до $100 \%$ об. [3]. Оптимальная концентрация этанола, при которой выход этаноллигнина максимален, не константа и в разных группах исследователей она разная. Например, исследование,

$$
\text { - } 437 \text { - }
$$


проведенное авторами [3], показало, что оптимальная концентрация этанола равна 75 \% об., в то время как, по данным работы [5], его оптимальная концентрация составляет 68 \% об. Продолжительность экстракции варьируется от 10 мин [3] до 4 ч [1] в зависимости от природы растительного сырья.

При исследовании технологических процессов химической переработки древесины часто применяют методы планирования эксперимента $[9,10]$. В литературе имеются публикации, посвященные применению подобных методов к исследованию процессов органосольвентной обработки древесины $[3,5,6]$.

В работе [5] выполнена оптимизация процесса экстракции пшеничной соломы водноэтанольными растворами различной концентрации, определены оптимальные параметры процесса, при которых выход глюкозы после ферментативного гидролиза целлюлозы будет максимальным. Для оптимизации применен полный факторный эксперимент для четырех основных параметров процесса: температура и продолжительность экстракции, концентрация катализатора (серной кислоты) и концентрация этанола в водно-этанольном растворе. Все параметры варьировались на двух уровнях. Полный факторный план позволил определить линейные коэффициенты регрессии и оценить возможные эффекты взаимодействия факторов. При увеличении температуры процесса с 160 до $210{ }^{\circ} \mathrm{C}$ возрастает степень делигнификации биомассы. Продолжительность экстракции в исследованном диапазоне (60 - 120 мин) не играет значительной роли. Увеличение количества катализатора (серная кислота) в диапазоне 0 - 30 ммоль/л приводит к значительному увеличению степени делигнификации биомассы. С ростом концентрации этанола в водно-этанольной смеси максимальное значение степени делигнификации биомассы достигается при его концентрации 68 \% об.

Большинство описанных в литературе результатов по исследованию процессов органосольвентной экстракции лигнинов получено в реакторах объемом не более $300-600$ мл [1, 3, 5]. Небольшой объем реактора способствует быстрому нагреву его содержимого до рабочих температур и быстрому охлаждению после проведения экстракции. Увеличение же объема реактора неизбежно приводит к увеличению инерционности процессов нагрева и охлаждения и, как следствие, к изменению продолжительности экстракции.

В данной работе представлены результаты исследования органосольвентной экстракции древесины лиственницы водно-этанольным раствором на укрупненной лабораторной установке с объемом реактора 2,4 л. Цель работы заключалась в определении влияния параметров процесса экстракции - температуры, концентрации этанола в смеси, продолжительности - на выход этаноллигнина из древесины лиственницы и выявление статистической взаимосвязи между температурой процесса и концентрацией этанола. Для установления оптимальных условий выделения этаноллигнина из древесины лиственницы создана математическая модель процесса водно-этанольной экстракции и проведен ее анализ.

\section{Экспериментальная часть}

Подготовка сырья к экстракциии

В экспериментах использовали древесину лиственницы сибирской (Larix sibirica). Стволовую часть древесины освобождали от коры и с помощью роторной мельницы РМ-120 перерабатывали в опилки размером менее 0,5 мм. Для определения содержания влаги и основных

$$
-438-
$$


компонентов опилки сушили в сушильном шкафу при температуре $(105 \pm 2){ }^{\circ} \mathrm{C}$ в течение 24 ч до постоянной массы. Содержание основных компонентов древесины лиственницы составляло (\% от массы абсолютно сухой древесины): целлюлоза Кюршнера - 45,85; лигнин - 29,45; пентозаны - 9,44; вещества, экстрагируемые водой - 12,08.

Экстракцию лигнина из воздушно-сухих опилок древесины лиственницы проводили в автоклаве из нержавеющей кислотостойкой стали с рабочим объемом 2,4 л в среде водного раствора этанола. Древесные опилки смешивали с водными растворами этанола непосредственно перед загрузкой в автоклав. Объем экстрагента необходимой концентрации составлял 1 л. Масса древесины во всех экспериментах составляла 100 г а.с. Спирто-древесную смесь загружали в автоклав, из реакционного объема удаляли воздух методом вытеснения аргоном при атмосферном давлении, герметизировали, троекратно продували током аргона для удаления остаточного воздуха, затем автоклав нагревали до рабочей температуры.

\section{Приборы и оборудование}

Нагрев автоклава производили электрической печью накаливания мощностью 1 кВт. Температуру регулировали изменением мощности нагрева при помощи автотрансформатора. Для контроля температуры в качестве датчика применялась термопара TXА и вторичный преобразователь - регистратор с бумажной диаграммной лентой. Давление в автоклаве контролировали с помощью манометра МПЗ - У. Скорость нагрева содержимого автоклава до заданной температуры составляла $4{ }^{\circ} \mathrm{C} /$ мин, до температуры $200{ }^{\circ} \mathrm{C}$ автоклав нагревался в течение 50 мин. Погрешность регулирования температуры составляла $\pm 5{ }^{\circ} \mathrm{C}$ - это обусловлено приборными погрешностями и тепловой инерционностью реактора. По достижению заданной продолжительности обработки печь отключали, далее реактор естественным образом охлаждался до комнатной температуры в среднем в течение 5 ч (300 мин). Экстракцию лигнина проводили без использования катализатора.

\section{Математическая модель проиесса экстракичии}

Для создания математической модели был применен полный факторный эксперимент $3^{2}-$ план Коно второго порядка (Ко-2) [10]. В качестве независимых факторов выбраны температура и концентрация этанола.

Границы диапазона варьирования температуры выбрали с учетом имеющихся в литературе данных [1-8], согласно которым при температурах экстракции ниже $180{ }^{\circ} \mathrm{C}$ выход лигнина резко падает, а при температуре свыше $230{ }^{\circ} \mathrm{C}$ выделенный лигнин начинает термически разлагаться [3]. С учетом этого диапазон изменения температуры выбрали следующий: нижний предел $\mathrm{T}_{-1}=180^{\circ} \mathrm{C}$, верхний предел $\mathrm{T}_{+1}=220^{\circ} \mathrm{C}$.

Также в литературе имеются сведения о резком уменьшении растворимости лигнина в водно-этанольных растворах при концентрациях этанола менее 50 и более $90 \%$ об. Поэтому были выбраны следующие пределы диапазона варьирования концентрации этанола: нижний предел $\mathrm{C}_{-1}=50$ \% об.; верхний предел $\mathrm{C}_{+1}=90$ \% об. [3].

\section{Методика выделения лигнина}

Выделение лигнина из экстракта проводили в соответствии с методикой, описанной в [5].

$$
-439-
$$


Выгрузку содержимого автоклава производили после охлаждения автоклава до комнатной температуры. Затем продукты реакции фильтровали на воронке Бюхнера при пониженном давлении, при этом твердый остаток промывали водным раствором этанола той же концентрации, что и реакционный раствор. Профильтрованный экстракт и промывные воды объединяли, охлаждали до $4{ }^{\circ} \mathrm{C}$ и выделяли из раствора этаноллигнин следующим образом. Полученный раствор разбавляли дистиллированной водой из соотношения 3 массовые части охлажденной до $4{ }^{\circ} \mathrm{C}$ воды к 1 части экстракта с промывными водами. Емкость с разбавленным и охлажденным экстрактом выдерживали при комнатной температуре в течение 12 ч для укрупнения осаждающегося этаноллигнина. Далее этаноллигнин фильтровали на воронке Бюхнера при пониженном давлении, промывая дистиллированной водой, и сушили при $50{ }^{\circ} \mathrm{C}$ в сушильном шкафу до постоянной массы. Выход этаноллигнина из древесины лиственницы определяли в расчете на а.с. состояние древесины.

Проведена статистическая обработка полученных экспериментальных результатов: для оценки границ погрешностей результатов в каждом эксперименте были определены статистические показатели - среднее квадратичное отклонение s и доверительный интервал погрешности при доверительной вероятности 95 \%. Предварительные эксперименты по определению влияния продолжительности варки на выход лигнина показали, что трех параллельных опытов на одну точку недостаточно для получения удовлетворительной точности. Поэтому количество параллельных опытов в последующем было увеличено до пяти.

\section{Результаты и обсуждение}

\section{Влияние продолжительности процесса экстракции на выход этаноллигнина} из древесины лиственницы

Из литературы [5] известно, что продолжительность процесса является наиболее значимым фактором при водно-этанольной экстракции соломы пшеницы.

Для исследования влияния продолжительности водно-спиртовой экстракции древесины лиственницы на выход этаноллигнина в качестве исходных параметров процесса были приняты: температура $200{ }^{\circ} \mathrm{C}$, загрузка 100 г древесины и 1 л водного раствора этанола с концентрацией $60 \%$ об.

На рис. 1 приведена зависимость выхода этаноллигнина от продолжительности экстракции в указанных условиях процесса. Каждый опыт повторяли 3 раза, за результат эксперимента принимали среднее значение выхода этаноллигнина, при этом погрешность определения не превышала $\pm 12 \%$ отн.

Как следует из полученных данных, выход этаноллигнина достигает максимума при продолжительности экстракции 150-180 мин. Максимальный выход этаноллигнина достигает 8,4 г (28,9 \% масс. от исходного содержания лигнина в древесине лиственницы).

\section{Математическая модель процесса экстракции этаноллигнина}

из древесины лиственниць

Для определения степени влияния таких параметров, как температура экстракции $(T)$ и концентрация этанола $(C)$, на экстракцию лигнина, а также взаимосвязи этих двух параметров проведен факторный эксперимент на основе В-плана второго порядка с центральной точкой [9]

$$
-440-
$$




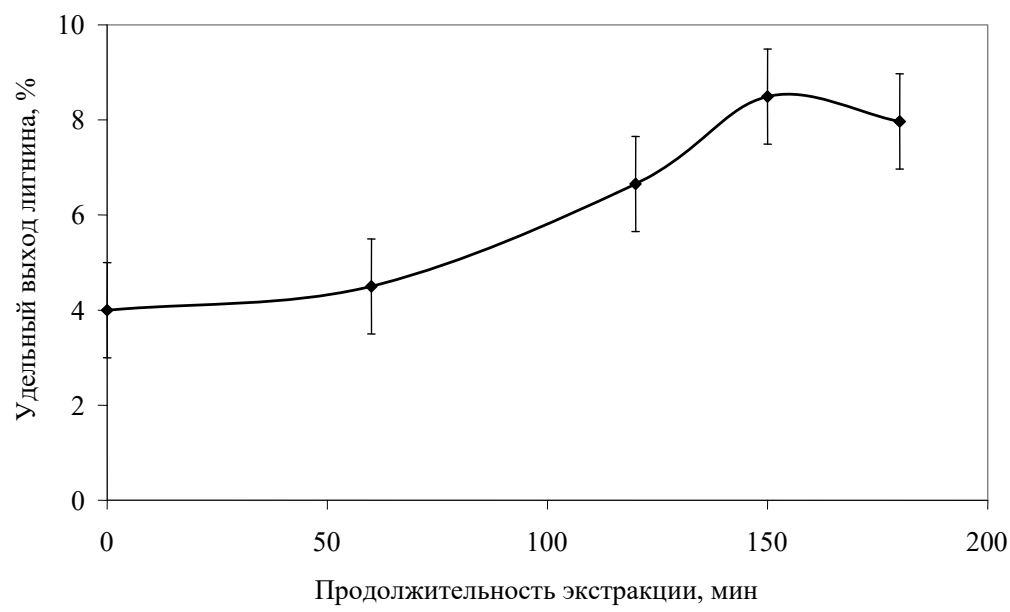

Рис. 1. Зависимость выхода этаноллигнина от продолжительности экстракции древесины лиственницы 60\%-м раствором этанола (1 л) при загрузке 100 г древесины лиственницы

Fig. 1. The dependence of the ethanollignin yield on the duration of extraction of larch wood with a $60 \%$ ethanol solution $(1 \mathrm{~L})$ when the loading of the larch wood is $100 \mathrm{~g}$

(план Ко-2 [10]). Такой план позволяет получить уравнение регрессии второго порядка и количественно оценить степень взаимосвязи двух факторов, а также при необходимости провести оптимизацию по заданному параметру.

Параметры процесса экстракции - температура $\left(T,{ }^{\circ} \mathrm{C}\right)$ и концентрация этанола $(C, \%$ об.) варьировались на трех уровнях. Границы изменения параметров были выбраны в соответствии с литературными источниками [1-7] и составляли: температура $T$ варьировалась от 180 до $220{ }^{\circ} \mathrm{C}$, концентрация этанола $C$ варьировалась от 50 до 90 \% об. Количество дублированных опытов в каждой точке равно 3 , уровень значимости $\mathrm{q}=0,05$.

Переменные факторы:

$X_{1}=T$ - температура варки, ${ }^{\circ} \mathrm{C}$;

$X_{2}=C-$ концентрация этанола, \% об.;

$y=m-$ выход лигнина, г.

Уровни варьирования факторов:

$X_{\text {Imin }}=180{ }^{\circ} \mathrm{C}, X_{10}=200{ }^{\circ} \mathrm{C}, X_{2 \max }=220^{\circ} \mathrm{C}$.

$X_{2 \min }=50 \%$ об., $X_{20}=70 \%$ об., $X_{2 \max }=90 \%$ об.

Нормализованные значения факторов:

$x_{1}=\frac{X_{1}-X_{10}}{20} ; x_{2}=\frac{X_{2}-X_{20}}{20}$.

Математическая модель в нормализованной форме:

$y=b_{0}+b_{1} \cdot x_{1}+b_{2} \cdot x_{2}+b_{11} \cdot x_{1}^{2}+b_{22} \cdot x_{2}^{2}+b_{12} \cdot x_{1} \cdot x_{2}$.

Условия, результаты эксперимента и нормализованные значения факторов приведены в табл. 1.

Дисперсия воспроизводимости единичного опыта равна: $s^{2}(y)=0,3261$.

Дисперсия воспроизводимости среднего значения из трех наблюдений $s^{2}\left(y_{c p}\right)=0,1087$.

Оценку значимости коэффициентов регрессии определяли из условия

$$
-441-
$$




$$
\left|b_{i i}\right| \leq t_{q} \cdot s\left(b_{i i}\right) \text {, }
$$

где $t_{q}=2,100922-t-$ критерий Стьюдента для уровня значимости $\mathrm{q}=0,05$ и количества степеней свободы $f_{l}=N \cdot(n-1)=9 \cdot(3-1)=18 ; s\left(b_{i j}\right)$ - дисперсия $b_{i i}$ коэффициента.

Коэффициенты регрессии и дисперсии коэффициентов определялись по методике, описанной в работе [10]. Значения коэффициентов регрессии и их дисперсий (для оценки значимости коэффициентов регрессии) приведены в табл. 2.

Уравнение регрессии в нормализованных обозначениях факторов $y=9,361+2,467 \cdot x_{1}+0,45 \cdot x_{2}-0,117 \cdot x_{1}^{2}-4,117 \cdot x_{2}^{2}-0,013 \cdot x_{1} \cdot x_{2}$.

Сравнение модулей коэффициентов $b_{i i}$ со значением $s\left(b_{i i}\right) \cdot t_{q}$ показывает, что коэффициент $b_{11}$ и коэффициент парных взаимодействий $b_{12}$ (условие (1)) незначимы, следовательно, их мож-

Таблица 1. Условия и результаты эксперимента по водно-этанольной экстракции древесины лиственницы

Table 1. Conditions and results of the experiment on water-ethanol extraction of the larch wood

\begin{tabular}{|c|c|c|c|c|c|c|c|}
\hline $\begin{array}{c}\text { № } \\
\text { опыта }\end{array}$ & $\begin{array}{c}\text { Температура } \\
(T),{ }^{\circ} \mathrm{C}\end{array}$ & $\begin{array}{c}\text { Концентрация } \\
\text { этанола }(C), \\
\text { \% об. }\end{array}$ & \multicolumn{2}{|c|}{$\begin{array}{c}\text { Нормализованные } \\
\text { факторы }\end{array}$} & $\begin{array}{c}\text { Выход лигнина } \\
\text { на 100 г } \\
\text { древесины, г }\end{array}$ & Дисперсия & $\begin{array}{c}\text { Расчетный } \\
\text { выход } \\
\text { лигнина, г }\end{array}$ \\
\hline $\boldsymbol{1}$ & $X_{1}$ & $X_{2}$ & $x_{1}$ & $x_{2}$ & $y$ & $\mathrm{~s}^{2}$ & $y_{\text {расч }}$ \\
\hline 1 & $\mathbf{2}$ & $\mathbf{3}$ & $\mathbf{5}$ & $\mathbf{6}$ & $\mathbf{7}$ & $\mathbf{8}$ \\
\hline 2 & 180 & 50 & -1 & -1 & 2,45 & 0,3241 & 2,33 \\
\hline 3 & 180 & 70 & -1 & 0 & 6,1 & 0,3325 & 6,89 \\
\hline 4 & 200 & 50 & -1 & +1 & 3,55 & 0,3111 & 3,23 \\
\hline 5 & 200 & 70 & 0 & 0 & 4,65 & 0,3361 & 4,79 \\
\hline 6 & 200 & 90 & 0 & +1 & 5,2 & 0,3342 & 9,36 \\
\hline 7 & 220 & 50 & +1 & -1 & 7,05 & 0,3283 & 7,26 \\
\hline 8 & 220 & 70 & +1 & 0 & 11,7 & 0,325 & 11,83 \\
\hline 9 & 220 & 90 & +1 & +1 & 8,1 & 0,3283 & 8,16 \\
\hline
\end{tabular}

Таблица 2. Значения коэффициентов регрессии

Table 2. Values of regression coefficients

\begin{tabular}{|l|c|c|c|c|c|c|}
\hline \multicolumn{1}{|c|}{$\begin{array}{c}\text { Обозначение } \\
\text { коэффициента } \\
\text { регрессии }\end{array}$} & $\mathrm{b}_{0}$ & $\mathrm{~b}_{1}$ & $\mathrm{~b}_{2}$ & $\mathrm{~b}_{11}$ & $\mathrm{~b}_{22}$ & $\mathrm{~b}_{12}$ \\
\hline $\begin{array}{l}\text { Значение } \\
\text { коэффициента } \\
\text { регрессии }\end{array}$ & 9,361 & 2,467 & 0,450 & $-0,117$ & $-4,117$ & $-0,013$ \\
\hline $\begin{array}{l}\text { Дисперсия } \\
\text { коэффициента } \\
s^{2}\left(b_{i j}\right)\end{array}$ & $\left(0,556 \cdot \mathrm{s}^{2}\left(y_{c p}\right)\right)^{*}$ & $\left(1,667 \cdot \mathrm{s}^{2}\left(\mathrm{y}_{\mathrm{cp}}\right)\right)$ & $\left(1,667 \cdot \mathrm{s}^{2}\left(\mathrm{y}_{\mathrm{cp}}\right)\right)$ & $\left(0,5 \cdot \mathrm{s}^{2}\left(\mathrm{y}_{\mathrm{cp}}\right)\right)$ & $\left(0,5 \cdot \mathrm{s}^{2}\left(\mathrm{y}_{\mathrm{cp}}\right)\right)$ & $\left(0,25 \cdot \mathrm{s}^{2}\left(\mathrm{y}_{\mathrm{cp}}\right)\right)$ \\
\hline $\begin{array}{l}\text { Значение параметра } \\
s\left(b_{i j}\right) \cdot t_{q}\end{array}$ & 0,060397 & 0,018119 & 0,018119 & 0,054357 & 0,054357 & 0,0271787 \\
\hline
\end{tabular}

Применение: "В скобках даны формулы, по которым рассчитывались значения $s^{2}\left(b_{i j}\right)$, где $i i$ - номер коэффициента [10]. 
но приравнять нулю. Поскольку планы Ко коэффициентов регрессии не требуется и уравнение регрессии в этом случае принимает вид

$$
y=9,361+2,467 \cdot x_{1}+0,45 \cdot x_{2}-4,117 \cdot x_{2}^{2} .
$$

\section{Анализ адекватности уравнения регрессии}

Для анализа адекватности регрессионной модели (2) вычисляли дисперсию адекватности: $s^{2}{ }_{a d}=0,8867$.

Расчетное значение критерия Фишера $F_{\text {расч }}=2,7186$. Табличное значение критерия Фишера $F_{\text {maб }}=2,77[9]$.

Соотношение $F_{\text {раси }}<F_{\text {таб }}$ выполняется, следовательно дисперсии $s_{a \dot{2}}^{2}$ и $s^{2}(y)$ однородны и можно считать, что полученное уравнение регрессии (2) адекватно описывает технологический процесс.

\section{Анализ уравнения регрессии}

Уравнение регрессии (2) в натуральных обозначениях факторов выглядит так:

$$
m(T, C)=-66,564+0,1221 \cdot T+1,4468 \cdot C-0,0101675 \cdot C^{2},
$$

где $m(T, C)$ - выход лигнина, г; $T$ - температура экстракции, ${ }^{\circ} \mathrm{C} ; C$ - концентрация этанола, \% об. Поверхность отклика изображена на рис. 2.

Зависимость выхода лигнина от температуры при фиксированных значениях концентрации этанола, рассчитанная по математической модели, приведена на рис. 3.

Анализ уравнения (3) показывает, что параметры $C$ и $T$ статистически независимы, поскольку отсутствует член полинома, отвечающий за парное взаимодействие.

Для температуры также отсутствует квадратичный член полинома, следовательно, при фиксированном значении концентрации этанола зависимость выхода лигнина от температуры будет линейной.

В исследованном диапазоне температур рассчитанные максимальные выходы этаноллигнина наблюдаются для концентраций этанола $\mathrm{C}=70$ \% об. Выход этаноллигнина в этом случае

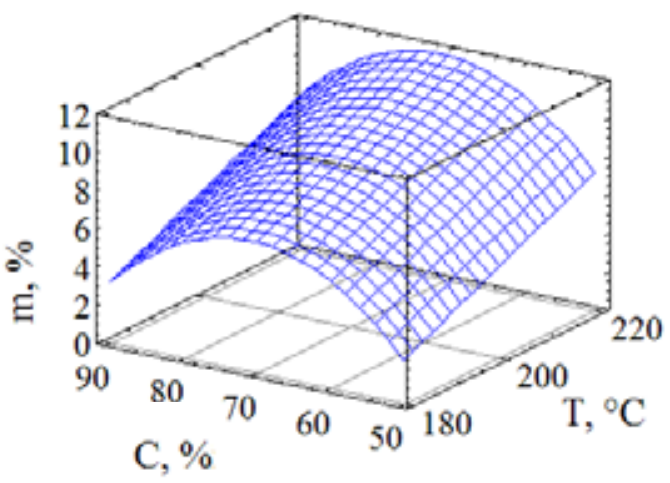

Рис. 2. Поверхность отклика, построенная по уравнению регрессии (3)

Fig. 2. The response surface based on the regression equation (3) 


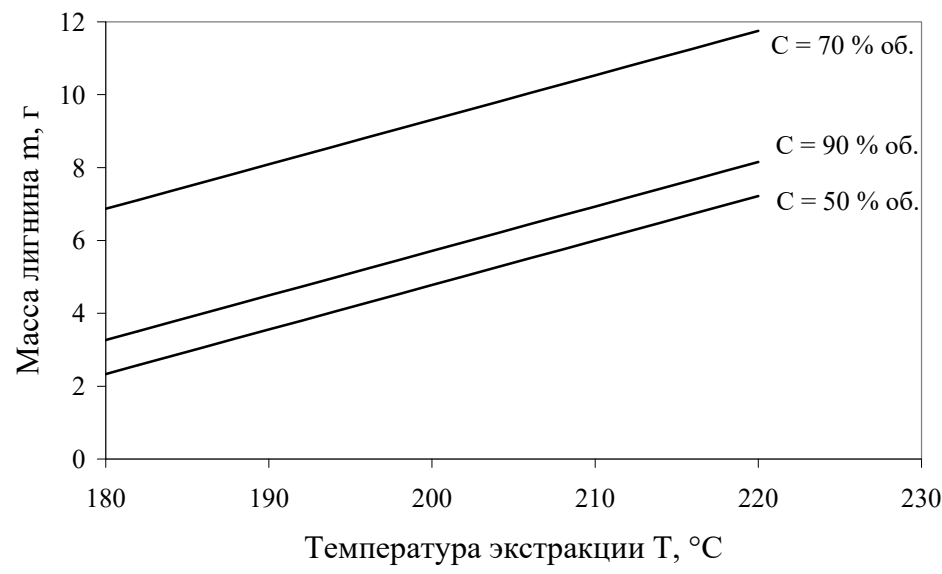

Рис. 3. Рассчитанные зависимости выхода этаноллигнина от температуры при фиксированных значениях концентрации водного раствора этанола и продолжительности экстракции 150 мин

Fig. 3. The calculated dependences of the ethanollignin yield on the temperature at fixed values of the ethanol aqueous solution concentration and the extraction duration of $150 \mathrm{~min}$

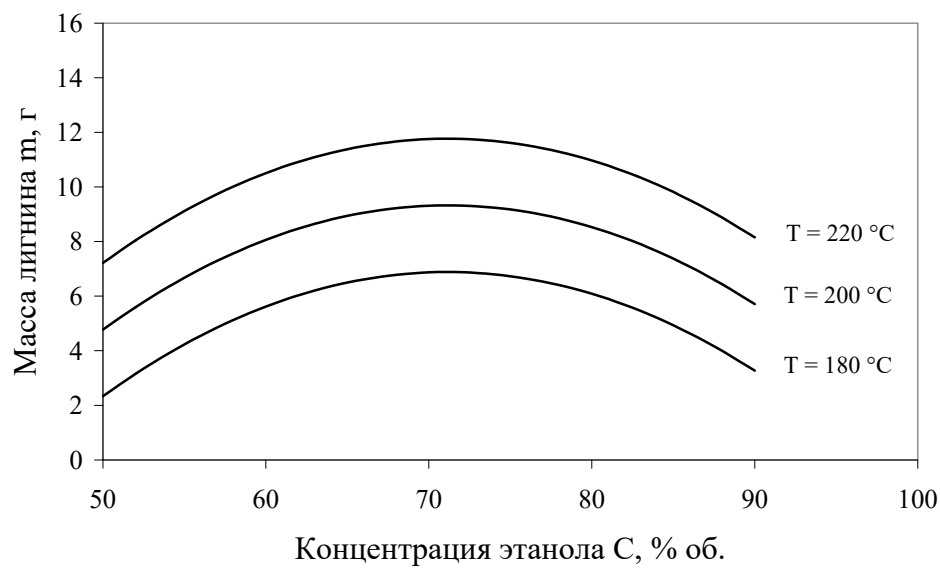

Рис. 4. Рассчитанные зависимости выхода лигнина от концентрации этанола при фиксированных температурах

Fig. 4. Calculated dependences of the lignin yield on the ethanol concentration at fixed temperatures

линейно растет с ростом температуры и составляет 6,89 и 11,83 г для температур 180 и $220^{\circ} \mathrm{C}$ соответственно.

Графики зависимости выхода этаноллигнина от концентрации этанола при фиксированных температурах можно видеть на рис. 4. Зависимость выхода этаноллигнина от концентрации водного раствора этанола в исследованном факторном пространстве более сложная, так как в уравнении регрессии присутствует квадратичный член. При различных фиксированных значениях температуры эта зависимость представляет собой семейство парабол, направленных ветвями вниз.

Поверхность отклика на факторном пространстве представляет собой параболический цилиндр, обращенный выпуклой стороной поверхности вверх (рис. 2). Максимальные выходы 
этаноллигнина соответствуют вершинам парабол и достигаются при концентрации этанола 70 \% об. Их расчетные значения составляют 6,89; 9,36 и 11,83 г при температурах экстракции 180,200 и $220^{\circ} \mathrm{C}$ соответственно (рис. 4). Максимальный расчетный выход этаноллигнина достигает 11,83 г при температуре экстракции $220^{\circ} \mathrm{C}$ и концентрации этанола $70 \%$ об., что соответствует 40,8 \% масс. от исходного содержания лигнина в древесине лиственницы.

\section{Заключение}

На укрупненной лабораторной установке с рабочим объемом реактора 2,4 л проведена оптимизация процесса водно-этанольной экстракции древесины лиственницы сибирской. Определены параметры многофакторного процесса экстракции, соответствующие максимальному выходу этаноллигнина: температура $200{ }^{\circ} \mathrm{C}$, продолжительность экстракции 150 мин, концентрация водного раствора этанола 70 \% об., масса загружаемой абсолютно сухой древесины 100 г. Экспериментальный выход этаноллигнина при этих условиях достиг 11,7 г (40 \% масс. от исходного содержания лигнина в древесине лиственницы).

Построена двухфакторная математическая модель второго порядка процесса водноэтанольной экстракции древесины, и показано, что она адекватно описывает процесс. В качестве независимых факторов для построения математической модели были выбраны температура экстракции и концентрация водного раствора этанола. Статистический анализ полученной математической модели выявил, что эти факторы статистически независимы.

В исследованном интервале температур $\left(180-220^{\circ} \mathrm{C}\right)$ расчетный выход лигнина линейно зависит от температуры. Зависимость выхода этаноллигнина от концентрации водного раствора этанола (50 - 90 \% об.) квадратичная. В исследованном диапазоне параметров самым существенный фактором, который влияет на выход этаноллигнина, является концентрация этанола, а второй по значимости фактор влияния - температура экстракции.

Исследование выполнено при частичной финансовой поддержке РФФИ (проект № 18 53-16001) в рамках базового проекта № 0356-2016-0503 (v.46.4.3).

\section{Список литературы}

1. Mingcun Wang., Mathew Leitch, Chunbao (Charles) Xu. Synthesis of phenol-formaldehyde resol resins using organosolv pine lignins. European Polymer Journal. 2009. Vol. 45, P. 3380-3388.

2. Min Zhang, Fernando L.P. Resende, Alex Moutsoglou. Catalytic fast pyrolysis of aspen lignin via Py-GC/MS. Fuel. 2014. Vol. 116, P. 358 - 369.

3. Joaquin Quesada-Medina, Francisco Javier Lopez-Cremades, Pilar Olivares-Carrillo. Organosolv extraction of lignin from hydrolyzed almond shells and application of the $\delta$-value theory. Bioresource Technology. 2010. Vol. 101, P. 8252-8260.

4. Yongjian $\mathrm{Xu}$, Kecheng Li, Meiyun Zhang. Lignin precipitation on the pulp fibers in the ethanol-based organosolv pulping. Colloids and Surfaces A: Physicochem. Eng. Aspects. 2007. Vol. 301, P. $255-263$.

5. Wildschut J., Smit A., Reith J., Huijgen W.J. Ethanol-based organosolv fractionation of wheat straw for the production of lignin and enzymatically digestible cellulose. Bioresource Technology. 2013. Vol. 135, P. 58-66. 
6. Mehmet Kuddusi Akalin, Selhan Karaguz, Mehmet Akyz. Supercritical ethanol extraction of bio-oils from German beech wood: Design of experiments. Industrial Crops and Products. 2013. Vol. 49, P. $720-729$.

7. Jae-Young Kim, Shinyoung Oh, Hyewon Hwang, Ung-Jin Kim, Joon Weon Choi. Structural features and thermal degradation properties of various lignin macromolecules obtained from poplar wood (Populus albaglandulosa). Polymer Degradation and Stability. 2013. Vol. 98, P. 1671-1678.

8. Xuebing Zhao, Keke Cheng, Dehua Liu. Organosolv pretreatment of lignocellulosic biomass for enzymatic hydrolysis. Applied Microbiology and Biotechnology. 2009. Vol. 82, P. 815 - 827.

9. Пижурин А.А., Розенблит М.С. Исследования процессов деревообработки. М.: Лесная промышленность, 1984. 232 с. [Pizhurin A.A., Rosenblit M.S. Woodworking process research. Moskow: The forest industry, 1984. 232 p. (In Russ.)].

10. Пен Р. З. Планирование эксперимента в Statgraphics. 2-е изд., дополненное. Красноярск: СибГТУ - Красноярский писатель, 2012. 270 с. [Pen. R.Z. Design of experiment. Krasnoyarsk: SibGTU, 2012. 270 p. (In Russ.)]. 